\title{
Unwinding and Rewinding: Double Faces of Helicase?
}

\author{
Yuliang Wu \\ Department of Biochemistry, University of Saskatchewan, Health Sciences Building, Saskatoon, SK, Canada S7N 5E5 \\ Correspondence should be addressed to Yuliang Wu, yuliang.wu@usask.ca
}

Received 12 April 2012; Accepted 28 May 2012

Academic Editor: Grigory Dianov

Copyright () 2012 Yuliang Wu. This is an open access article distributed under the Creative Commons Attribution License, which permits unrestricted use, distribution, and reproduction in any medium, provided the original work is properly cited.

\begin{abstract}
Helicases are enzymes that use ATP-driven motor force to unwind double-stranded DNA or RNA. Recently, increasing evidence demonstrates that some helicases also possess rewinding activity-in other words, they can anneal two complementary singlestranded nucleic acids. All five members of the human RecQ helicase family, helicase PIF1, mitochondrial helicase TWINKLE, and helicase/nuclease Dna2 have been shown to possess strand-annealing activity. Moreover, two recently identified helicases-HARP and $\mathrm{AH} 2$ have only ATP-dependent rewinding activity. These findings not only enhance our understanding of helicase enzymes but also establish the presence of a new type of protein: annealing helicases. This paper discusses what is known about these helicases, focusing on their biochemical activity to zip and unzip double-stranded DNA and/or RNA, their possible regulation mechanisms, and biological functions.
\end{abstract}

\section{Introduction}

Helicases are molecular motors that couple the energy of nucleoside triphosphate hydrolysis to the unwinding and remodeling of structured DNA or RNA [1-3]. The number of helicases expressed in higher organisms is strikingly high, with approximately $1 \%$ of the genes in many eukaryotic genomes apparently encoding RNA or DNA helicases. Helicases are involved in virtually all aspects of nucleic acid metabolism, including replication, repair, recombination, transcription, chromosome segregation, and telomere maintenance [4-7]. Based on their substrates, helicases can be classified as DNA or RNA helicases, although some can function on both DNA and RNA molecules [8]. DNA helicases have been reported to function in a variety of DNA metabolic processes, including unwinding duplex or alternative DNA structures (triplex, G-quadruplex), stripping protein bound to DNA, and chromatin remodeling $[5,6,9,10]$.

Traditionally, helicases are known to unwind doublestranded DNA or RNA in an ATP-dependent manner. However, increasing evidence suggests that some helicases can rewind, or anneal, complementary strands of polynucleic acids in the presence or absence of nucleoside triphosphate (Figure 1). Moreover, two so-called human helicases that were identified recently appear to only have ATP-dependent rewinding activity [11-15]. These discoveries not only enrich the definition of helicases but also establish the presence of a new type of protein: annealing helicase. The mechanism of this novel strand annealing activity and its biological consequences remain largely unknown. In this paper, I will provide a brief overview of strand annealing activity found in various proteins across species and then focus on annealing helicases in humans and their potential mechanisms and functions.

\section{Proteins with Strand Annealing Activity}

Most knowledge regarding the strand annealing activity of proteins has come from studies of model systems, including bacteria, yeast, and Xenopus laevis. The Lehman lab reported the ATP-dependent annealing activity of purified recombinant Escherichia coli RecA protein three decades ago [16]. Although similar results were obtained by several other labs [17-19], the annealing activity of RecA (the human RAD51 homolog) is likely due to the binding of single-stranded DNA (ssDNA), which forms a nucleoprotein filament. The RecA (RAD51) searches for homology along double-stranded DNA (dsDNA) and forms a stretching of DNA duplex. Two other bacterial proteins-regulator protein StpA and recombination mediator protein $\mathrm{RecO}$ - have been reported to promote annealing of complementary single stranded RNA (ssRNA) and ssDNA, respectively $[20,21]$. The DNA 


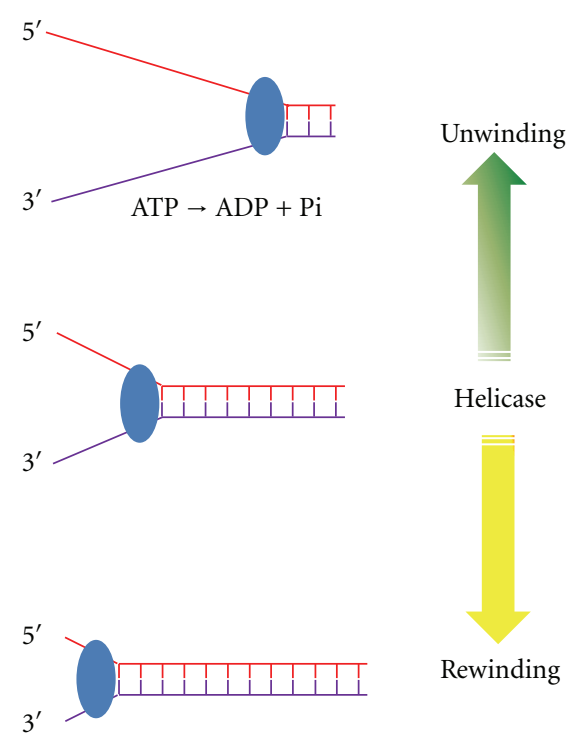

Figure 1: A model of helicase function to unwind or rewind double-stranded nucleic acid. Note that helicase (oval) represents both translocation polarities; either ATP-dependent or ATPindependent for strand annealing activity has been observed in helicases (see Table 1).

replication polymerase (Dpo1) of Sulfolobus solfataricus also possesses strand annealing activity [22]. In yeast, the Rothstein lab first found that Rad52 protein binds ssDNA and dsDNA and promotes strand annealing [23]. Later, the Kowalczykowski lab demonstrated that Rad51 and Replication Protein A (RPA) regulate Rad52's annealing function [24-26]. Another yeast protein, Rad59, also stimulates complementary ssDNA annealing $[27,28]$. Xenopus RNAbinding protein X1rbpa was reported to promote RNA : RNA annealing [29]. Interestingly, strand annealing activity has also been reported for some viral proteins. For example, Tat, one of six HIV regulatory proteins, encodes a small nuclear transcriptional activator and stimulates DNA : DNA annealing [30, 31]; dengue virus core protein also promotes RNA : RNA annealing [32].

Several mammalian proteins have been found to possess annealing activity. The Wilson lab first reported that rat heterogeneous nuclear ribonucleoprotein (hnRNP) A1 has strand annealing activity on both DNA and RNA [33], and the activity is inhibited by phosphorylation of kinase PKA or PKC. The annealing activity is restored by dephosphorylation of hnRNP by phosphatase $2 \mathrm{~A}[34,35]$. Mouse p53 protein inhibits the unwinding activity of $\mathrm{T}$ antigen helicase in vitro [36]; human p53 protein was also later found to inhibit several other helicases' unwinding activity due to its strong DNA:DNA and RNA: RNA annealing activity [37]. Human Mre11 complex mediates the annealing of complementary ssDNA molecules [38]. The human RAD51B, RAD51C, RAD51D, and XRCC2 protein complex catalyzes the strand-annealing reaction between a long linear ssDNA (1.2 kb in length) and its complementary circular ssDNA [39]. In summary, at least a dozen proteins, particularly those involved in DNA replication and repair, have been demonstrated to possess strand annealing activity. However, it is surprising to find that helicases, which unwind double stranded DNA or RNA, also possess strand annealing activity.

\section{The Discovery of the Annealing Activity of Helicases}

The annealing activity was first reported in RNA helicases (Table 1). In 1997, the Busch lab reported that human RH II/Gu RNA helicase has RNA folding activity-forming an intramolecular duplex [40]. In 2001, the Stahl lab discovered that RNA helicase $\mathrm{p} 68$ and its close relative $\mathrm{p} 72$ possess RNA annealing activity for two complementary RNA strands [41], and they also showed that Ddx42p, another p68 homolog, has similar activity [42]. RNA helicase A, also known as nuclear DNA helicase II or DHX9, is a superfamily 2 (SF2) helicase that unwinds DNA-DNA, RNA-RNA, and DNARNA strands with a $3^{\prime}-5^{\prime}$ polarity [43]. Recently, it was reported that RNA helicase A promotes the annealing of $\mathrm{tRNA}_{3}{ }^{\text {Lys }}$, the primer for reversing transcription, to HIV1 RNA [44]. In addition to human RNA helicases, some yeast and bacterial RNA helicases also contain annealing ability. For example, the Jankowsky lab demonstrated that DED1 from Saccharomyces cerevisiae, in addition to its RNA unwinding activity, facilitates the formation of RNA duplexes [45]. The Lambowitz lab found that Mss116p of S. cerevisiae promotes the annealing of the oligonucleotides in the absence of ATP [46]. CrhR, a cyanobacterial RNA helicase, was also found to promote duplex formation in the presence of ATP [47]. Dengue virus RNA helicase NS3 accelerates RNA annealing in the absence of ATP [48].

Compared with RNA helicase, more DNA helicases have been found to possess annealing activity (Table 1). The Janscak lab is the first to report that both unwinding and annealing activity resided in a DNA helicase, RECQ5 $\beta$ in 2004 [55]. RECQ5 $\beta$ is the longer isoform of RECQ5 helicase and is localized in the nucleus. The Janscak lab not only discovered the novel activity of RECQ $5 \beta$, but also mapped the unique C-terminal portion (aa 411-991) that possesses the DNA strand-annealing activity [55]. This was the first demonstration of a DNA helicase with an intrinsic DNA annealing function residing in a separate domain of the same polypeptide (Figure 2). Subsequently, many helicases, particularly RecQ family helicases, have been found to possess annealing activity. In humans, there are five RecQ homologs, and mutations in three of these genes (BLM, WRN, and RECQ4) are associated with Bloom's, Werner, and Rothmund-Thomson syndromes, respectively. Although no disease has been linked to mutations of RECQ5, recq $5^{-/-}$mice are highly cancer prone and display genomic instability $[60,61]$. A single nucleotide polymorphism in RECQ1 correlates with decreased survival of pancreatic cancer patients $[62,63]$. Annealing activity was reported for the Bloom's syndrome helicase, BLM, in 2005 by two independent groups $[51,53]$. Recently, the Brill lab further identified a subdomain of the BLM/Sgs1 N-terminus that contains annealing activity in vitro [64]. Not only do human BLM and yeast Sgs1 display annealing activity, so does the 
TABLE 1: Human helicases containing annealing activity.

\begin{tabular}{|c|c|c|c|c|}
\hline Helicases & $\begin{array}{l}\text { Unwinding activity } \\
\text { (Polarity) }\end{array}$ & $\begin{array}{c}\text { ATP requirement } \\
\text { for annealing } \\
\text { activity }\end{array}$ & Other activities & References \\
\hline RNA helicase II (Gu, DDX21) & $\sqrt{ }$ & - & & {$[40]$} \\
\hline p68 family (p72, Ddx42p) & $\sqrt{ }$ & $\begin{array}{l}+(D d x 42 p) \\
-(p 68, p 72)\end{array}$ & & {$[41,42]$} \\
\hline RNA helicase A (DHX9) & $\sqrt{ }\left(3^{\prime}-5^{\prime}\right)$ & + & & {$[44]$} \\
\hline RECQ1 & $\sqrt{ }\left(3^{\prime}-5^{\prime}\right)$ & - & & {$[49,50]$} \\
\hline WRN & $\sqrt{ }\left(3^{\prime}-5^{\prime}\right)$ & - & $3^{\prime}$ to $5^{\prime}$ exonuclease & {$[51,52]$} \\
\hline BLM & $\sqrt{ }\left(3^{\prime}-5^{\prime}\right)$ & - & & {$[51,53]$} \\
\hline RECQ4 & $\sqrt{ }\left(3^{\prime}-5^{\prime}\right)$ & - & & {$[54]$} \\
\hline RECQ5 $\beta$ & $\sqrt{ }\left(3^{\prime}-5^{\prime}\right)$ & - & & {$[55]$} \\
\hline Pif1 & $\sqrt{ }\left(5^{\prime}-3^{\prime}\right)$ & - & & {$[56]$} \\
\hline Dna2 & $\sqrt{ }\left(5^{\prime}-3^{\prime}\right)$ & - & $\begin{array}{l}5^{\prime} \text { to } 3^{\prime} \text { endonuclease; } \\
3^{\prime} \text { to } 5^{\prime} \text { exonuclease }\end{array}$ & {$[57]$} \\
\hline CSB & & - & & {$[58]$} \\
\hline HARP (SMARCAL1) & & + & & {$[11-14]$} \\
\hline $\mathrm{AH} 2$ & & + & & {$[15]$} \\
\hline TWINKLE & $\sqrt{ }\left(5^{\prime}-3^{\prime}\right)$ & - & & {$[59]$} \\
\hline
\end{tabular}

Note: "+" stands for ATP is required; “-” for ATP not required.

Drosophila BLM homolog (mus309/DmBLM) [51, 64, 65]. The WRN helicase was reported to contain strand pairing activity [51], and the annealing activity was mapped to the C-terminal region (aa 1072-1150) [52]. Annealing activity was also found for human RECQ1 protein by the Brosh lab [49]. Later, the Vindigni lab reported that RECQ1 efficiently promotes strand annealing as a higher order oligomer (pentamer or hexamer), while smaller oligomeric states (dimer or monomer) act to unwind duplex DNA [50]. Different quaternary states of RECQ1, modulated by binding of ssDNA and ATP, are associated with its strand annealing or unwinding activity (discussed later).

Unlike other RecQ helicases, neither endogenous RECQ4 purified from HeLa cell extracts [67] nor recombinant RECQ4 purified from E. coli [68] originally showed unwinding activity. The unwinding activity of RECQ4 appears to have been masked by its strong intrinsic DNA annealing activity [54, 69]. Because of its robust annealing activity, the presence of a third strand (e.g., same sequence as the labelled oligo but unlabelled) is required to demonstrate unwinding by RECQ4. Furthermore, the N-terminus (aa 1492) is required for the annealing activity of RECQ4 [54]. Although it was later reported that RECQ4 could displace short oligonucleotides ( $\leq 22 \mathrm{mer}$ ) without a third strand, the fact that longer oligonucleotides $(\geq 30$ mer) require a third strand $[69,70]$ indicates the strong annealing activity resides in the RECQ4 peptide.

In addition to the RecQ helicase family, several other DNA helicases possess strand annealing activity too (Table 1). The Pif1 helicase family is a group of $5^{\prime} \rightarrow 3^{\prime}$ directed, ATP-dependent, super-family IB helicase that is found in nearly all eukaryotes [71]. The purified recombinant human PIF1 proteins display robust annealing activity without ATP, and this activity resides in the N-terminal region (aa 1-180) of the protein [56] (Figure 2). Dna2 is a helicase and nuclease involved in Okazaki fragment processing, double-strand break (DSB) repair, telomere regulation, and mitochondrial function [72]. Both yeast and human DNA2 protein contain strand annealing properties. Point mutation analysis revealed that the annealing activity does not require either the nuclease or the helicase activity of Dna2 [57], indicating that the rewinding activity is uncoupled from nuclease and/or unwinding activity. Mutations in CSB gene cause Cockayne syndrome, a rare inherited genetic disorder characterized by UV sensitivity, severe neurological abnormalities, and progeroid symptoms [73]. The CSB protein catalyzes strand annealing of complementary ssDNA, while both ATP and RPA inhibit its annealing activity [58]. TWINKLE is a human mitochondrial DNA helicase that is associated with heritable neuromuscular diseases, and it has NTP-independent annealing activity [59]. The T4 phage UvsW helicase [74] two archaea helicases (Hjm/Hel308A [75] and Hel112 [76]), and Mycobacterium tuberculosis XPB [77] also contain strand annealing activities.

\section{Annealing Helicases HARP and AH2}

The term "annealing helicase" was created when two helicase domain-containing proteins were discovered to possess annealing activity and no unwinding activity. In 2008, the Kadonaga lab discovered that HARP is an ATP-dependent annealing helicase [14]. HARP (HepA-related protein), also 


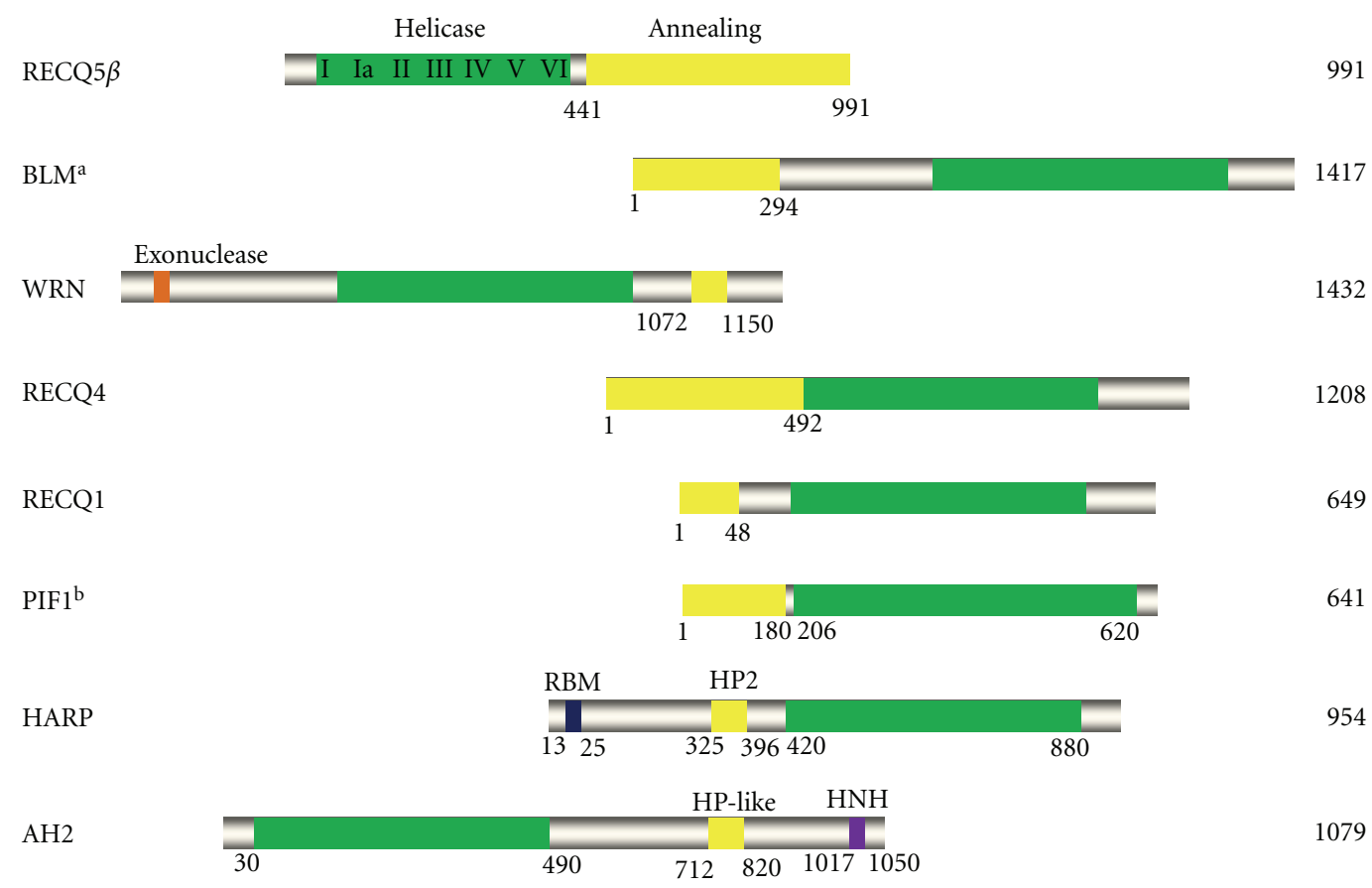

FIGURE 2: Alignment of human DNA helicases that contain annealing activity. The annealing domain is indicated in yellow and the conserved helicase core domain in green; the conserved seven helicase motifs and the accessory domains are indicated. HP2, HepA-related protein domain 2; RBM, RPA-binding motif; HNH refers to the three conserved His and Asn amino acid residues in the motif. The total number of amino acids in each helicase protein is shown to the right. (a) It was reported that the C-terminus of BLM is important for its strandannealing function [51, 53]; (b) it was also reported that the helicase core domain of PIF1 has annealing activity [66]. The functional annealing activity domain for CSB, TWINKLE, and Dna2 has not been mapped.

known as SMARCAL1 (SWI/SNF-related, matrix-associated, actin-dependent regulator of chromatin, subfamily a-like 1), is a member of the SWI/SNF family protein. Mutations in HARP are associated with Schimke Immuno-Osseous Dysplasia (SIOD), a multisystem autosomal recessive disorder characterized by short stature, kidney disease, and a weakened immune system [78]. The majority of SIOD patients have T-cell deficiency and associated risk for opportunistic infection, a common cause of death. Loss of HARP affects cellular proliferation and differentiation, and the response to replication stress [79]. Following the Kadonaga lab's report, three other labs found similar enzymatic activity for HARP and further defined its biological functions [11-13]. HARP binds directly to RPA via a conserved $\mathrm{N}$-terminal motif and anneals RPA-coated complementary ssDNA. It was proposed that HARP might dictate its role in the S-phase-specific DNA damage response to protect stalled replication forks by minimizing the accumulation of ssDNA regions and facilitating the repair of collapsed replication forks [11$13,80]$. Similar results were also obtained for HARP in a $X$. laevis system [81]. The Chen lab further identified that two HP domains, each has about 60 residues, dictate the annealing activity of HARP [82]. More recently, the Cortez lab reported that the first HP domain is not required for annealing activity, and, intriguingly, HARP is able to catalyze branch migration of Holliday junctions (HJs) and regression of replication forks [83].
After discovering the unique activity of the HARP protein, the Kadonaga lab identified another annealing helicase that they named annealing helicase 2 (AH2) [15]. AH2 was previously named ZRANB3 (zinc-finger, RANbinding domain containing 3), a member of the Snf2 family [84]. Similar to HARP, the purified recombinant AH2 protein displays DNA-dependent ATPase activity and ATPdependent rewinding activity. However, unlike HARP, AH2 lacks a conserved RPA-binding domain and does not interact with RPA. In addition, $\mathrm{AH} 2$ contains an $\mathrm{HNH}$ motif at its extreme C-terminus (Figure 2), which is common in prokaryotes and is often associated with nuclease activity [85]. Contrary to expectations, the purified recombinant AH2 protein does not exhibit nuclease activity [15]. With no disease linked to $\mathrm{AH} 2$ or genetic model generated for $\mathrm{AH} 2$, the biological function of $\mathrm{AH} 2$ remains largely unknown.

Interestingly, the direction of both annealing helicases (HARP and AH2) has not been examined in vitro. Since classic DNA-dependent ATPases that are bonafide helicases that have the ability to catalytically separate complementary strands behave in a directional manner with respect to the strand that the helicase protein is presumed to be bound, depend on which we define $3^{\prime}-5^{\prime}$ or $5^{\prime}-3^{\prime}$ helicase, therefore, it would be of interest to know whether HARP or AH2 translocate in a directionally specific manner. 


\section{Possible Mechanisms of Helicase Annealing Activity}

Specific helicases need to function on the appropriate nucleic acid substrate at the appropriate time. In addition, these enzymes might be required to facilitate unwinding and/or rewinding under different circumstances. Indeed, several Bloom's syndrome missense mutant proteins lack unwinding activity, but still possess strand annealing activity that is even greater than wild type BLM [86], indicating that the misregulation of unwinding and rewinding activity may be one of the pathogenic factors. A key emerging question is how these two opposite activities of helicase are precisely regulated.

\subsection{Do Helicases Contain an Annealing Domain? Helicase} is characterized by conserved helicase motifs. The number of helicase motifs varies from seven, nine, to twelve, which are responsible for nucleic acid binding, NTP hydrolyzing, and DNA or RNA unwinding $[2,87]$. Some helicases also contain accessory domain(s) at the N-or C-terminus, such as nuclease domain and various protein-protein interaction domains. As shown in Figure 2, studies of human BLM helicase and its orthologs including budding yeast Sgs1 and Drosophila BLM revealed that its $\mathrm{N}$-terminal region contains strand annealing activity [64]. Studies of the RecQ5 $\beta$ helicase revealed that the $\mathrm{C}$-terminus is responsible for its annealing activity [55]. The annealing activity of PIF1 resides in its $\mathrm{N}$-terminal domain [56]. Furthermore, studies of RECQ4 protein revealed that some missense mutants lose unwinding activity but still possess strand annealing activity [54]. These results suggest that the DNA unwinding and strand annealing activities can be uncoupled, but the question remains whether there is a conserved domain that controls annealing activity.

The Cortez lab found that only the second HP domain is required for the annealing activity of HARP [83] (Figure 2). Alignment of the HP domain with $\mathrm{AH} 2$ reveals a putative "HP-like" domain in the $\mathrm{AH} 2$ protein (residues 712-820) [82]. Although HP domain-like amino acids are found in the $\mathrm{AH} 2$, it is unlikely that the HP domain is a universal element that governs annealing activity across helicases. For example, the N-terminal region (residue 156) of RECQ1 [88] and the C-terminal region (aa 10721150) of the WRN helicase [52] are required for their respective annealing activities. Alignment of the "annealing domains" of these two RecQ helicases with the HP domains present in HARP and the HP-like domain in AH2 reveals no significant conserved residue. Although the $\mathrm{N}$-terminal domain of RECQ4 and the C-terminal region of RECQ5 share certain identity and similarity, alignment of the N-terminus of RECQ4 and BLM, and the C-terminus of RECQ5 does not result in any significant homology (data not shown). Thus, it is unlikely that a single conserved domain is responsible for the annealing activity of these helicases. More conclusive data will be obtained when more annealing helicases are identified.
5.2. Protein Oligomerization Affects Helicase Rewinding Activity. Certain helicases may self-assemble to form dimers or higher order oligomers, and this can influence their catalytic activity or biological function [1-3]. Thus, oligomerization might be important for the regulation of helicase annealing activity. Human RECQ1 helicase efficiently promotes strand annealing as a higher order oligomer (tetramer) while smaller oligomeric states (dimer or monomer) acting to separate duplex DNA $[50,88]$. Electron microscopy reconstructions of the higher order oligomeric form revealed that a cage-like structure forms a hollow channel, which may facilitate the annealing activity of RECQ1 [50]. Both consistent and inconsistent with the findings of RECQ1, Hel112, a homologue of human RecQ5 $\beta$ in Sulfolobus solfataricus, exists as two predominant stable oligomeric states: monomer and dimer. Only the monomeric form has $3^{\prime}-5^{\prime}$ DNA-helicase activity, while both the monomer and the dimer possess strand-annealing activity [76]. These findings raise the possibility that higher order oligomers promote annealing activity and smaller order oligomers promote unwinding activity. Nevertheless, additional studies are needed to address the relationship between the oligomerization and dual activities of helicases.

5.3. Does ATP Act as a Switch between the Unwinding and Rewinding Activity of Helicases? For helicases that possess unwinding activity, it makes sense that ATP fuels the unwinding activity, in turn, inhibits the annealing activity. Indeed, this has been seen in DNA helicases such as BLM [53], Pif1 [56], as well as the E. coli Cas3 helicase [89]. It was also reported that, for the RNA helicase Ddx42p, ATP triggers RNA strand separation while ADP triggers annealing of complementary RNA strands [42]. However, for helicases with no detectable unwinding activity, it is largely unknown how ATP regulates their annealing activity. For example, how ATP inhibits CSB's annealing activity [58], while HARP and $\mathrm{AH} 2$ require ATP $[14,15]$.

Rather than fueling the unwinding activity by hydrolyzing ATP, ATP binding might cause a conformational change in the helicase that prevents annealing. For example, the strand-annealing activity of RECQ5 $\beta$ is strongly inhibited by ATP $\gamma \mathrm{S}$, a poorly hydrolyzable analog of ATP. This effect is alleviated by mutations in the ATP-binding motif of RECQ5 $\beta$, indicating that the ATP-bound form of the protein cannot promote strand annealing [55]. ATP $\gamma S$ also inhibits the annealing activity of BLM [51], WRN [51], and CrhR helicases [47]. For RECQ1, ATP binding induces a conformational change in the protein that serves as a molecular switch from a strand-annealing to a DNAunwinding mode [49]. If ATP indeed functions as a switch to regulate or balance the unwinding and rewinding activity of helicases, a promising avenue for future research will be to investigate the regulation mechanism, for example, structural determination of helicases with and without ATP.

5.4. Other Proteins Regulate Helicase Annealing Activity. RPA is a fundamental protein involved in all aspects of cellular metabolism (see review $[90,91]$ ). In DNA 
repair processes, RPA physically coats ssDNA to protect it from degradation by nucleases and also serves as a scaffold protein to recruit other repair proteins (e.g., Rad51) to strand break sites. At the same time, RPA promotes checkpoint signaling after replication fork stalling through activation of ATR-ATRIP and RAD17 complexes. RPA has been shown to stimulate the unwinding activity of many helicases in vitro, including WRN [92, 93], BLM [94], RECQ1 [95], and FANCJ [96]. In turn, the strand annealing activity of RECQ1 [49], PIF1 [56], and CSB [58] is inhibited by RPA. In contrast, the unwinding activity of RECQ4 is inhibited by RPA [68]. RPA depletion causes a dramatic reduction in the formation of the annealing products in Xenopus egg extracts, suggesting that RPA is required for single-strand annealing [97]. The annealing helicase HARP associates with RPA, but whether it is just a physical interaction or if RPA modulates HARP's annealing function remains unknown. For AH2, yet to be identified proteins may regulate its nuclease and/or annealing activity.

In addition to RPA, several other proteins have been shown to promote annealing activity of helicases. The $65 \mathrm{kDa}$ subunit of U2AF is reported to mediate the annealing of complementary single-stranded RNA or single-stranded DNA, which reverses the action of RNA helicase A [98]. The purified human p53 protein inhibits the unwinding activity of several DNA helicases, such as T antigen DNA helicase, DNA helicases I and II of E. coli, and RNA helicases p68, by promoting the rapid renaturation of complementary strands [37]. The endonuclease XPG is also reported to stimulate the annealing activity of the WRN helicase [99].

5.5. Post-Translational Modification of Helicases. Catalytic activities of proteins can be modulated by posttranslational modifications, such as phosphorylation/dephosphorylation, acetylation, ubiquitination, and SUMOylation. For example, endogenous RECQ1 is phosphorylated upon treatment of cells with ionizing radiation (IR), Ultraviolet (UV), and hydroxyurea (HU) [100]; BLM is phosphorylated by ATM in response to IR $[101,102]$, ATR in response to $\mathrm{HU}$ [103], and several other kinases-CK1 [104], cdc2 [105], and MPS1 [106]. WRN is phosphorylated by ATM and ATR in response to replication fork arrest [107, 108]. BLM is a SUMO substrate and SUMO modification regulates BLM's intranuclear localization [109]. WRN is acetylated by the acetyltransferase p300 [110]. HARP is phosphorylated by ATM, ATR, and DNA-PK in response to the DNA damage checkpoint $[11,81]$. Indeed, the strand annealing activity of CSB is increased by dephosphorylation with phosphatase I and decreased by phosphorylation with CKII [58]. Thus, helicase function may in specific cases be regulated by post translational modification through modulation of its strand annealing activity. Nevertheless, it remains largely unknown how annealing activity is modulated by these protein modifications.

\section{Cellular and Biological Significance of Helicase Annealing Activity}

The biological function of so-called real helicases, which possess unwinding activity that includes RecQ family helicases [4, 6], Pif1 [71], and Dna2 [72], has been extensively reviewed. The focus here is on annealing activity of helicases. The physiological relevance of helicase annealing activity is revealed by the finding that several mutations observed in SIOD patients result in defective annealing activity in HARP protein $[14,78,111]$. Although a limited number of annealing helicases have been identified, several biological functions have been indicated by related experimental evidence.

6.1. Stabilization of the Stalled Replication Fork. Stalled replication forks can arise during normal chromosome replication or in the presence of DNA lesions, but will collapse if being left unrepaired due to the presence of long stretches of ssDNA. Annealing helicases might stabilize stalled replication forks through pairing the parental ssDNA, migrating chicken foot/Holliday junctions structures, and/or directly participating in repair of the lesion (Figures 3(a) and $3(\mathrm{~b})$ ). Green fluorescent protein (GFP)-tagged HARP is recruited to stalled replication forks [11]. Compared with ssDNA and dsDNA, fork DNA is a preferred substrate for AH2 binding and ATPase activity [15], indicating that the forked DNA is a physical substrate for AH2. Because HARP and $\mathrm{AH} 2$ can act as an opposing force to unwinding activities in vivo, there are obvious potential implications for the role of HARP and AH2 in DNA replication and DNA repair activities (discussed below). HARP and AH2 might dictate their role in protecting stalled replication forks by minimizing the accumulation of ssDNA regions and facilitating the repair of collapsed replication forks during DNA replication [112]. Consistent with its function on ssDNA, four research groups have found that HARP associates with the RPA complex $[11-13,81]$, which possibly anchors HARP to the ssDNA. Cells depleted of HARP accumulate ssDNA and display increased sensitivity to aphidicolin and HU $[12,13]$. DNA fibre analyses show that restart of replication forks after 2 hours of aphidicolin treatment is reduced in HARP-depleted cells $[11,81]$. These data suggest that HARP promotes fork stability and restart by reannealing long stretches of ssDNA generated at stalled replication forks. Indeed, very recently, the Cortez lab demonstrated that in vitro HARP can bind and branch-migrate three-way and four-way DNA structures, and catalyze extensive fork regression of model replication forks [83].

The RecQ family helicases have been well recognized to function in damaged replication forks [113]. WRNdeficient cells are hypersensitive to replication blocking agents, including HU $[107,114]$ and DNA-interstrand crosslinking drugs [115]. BLM-deficient cells are also hypersensitive to HU [103] and Mitomycin C (MMC) [116]. Although less sensitive to HU as BLM-deficient and WRNdeficient cells, RECQ4-deficient cells are sensitive to HU [117]. RECQ1-depleted human cells are sensitive to HU 


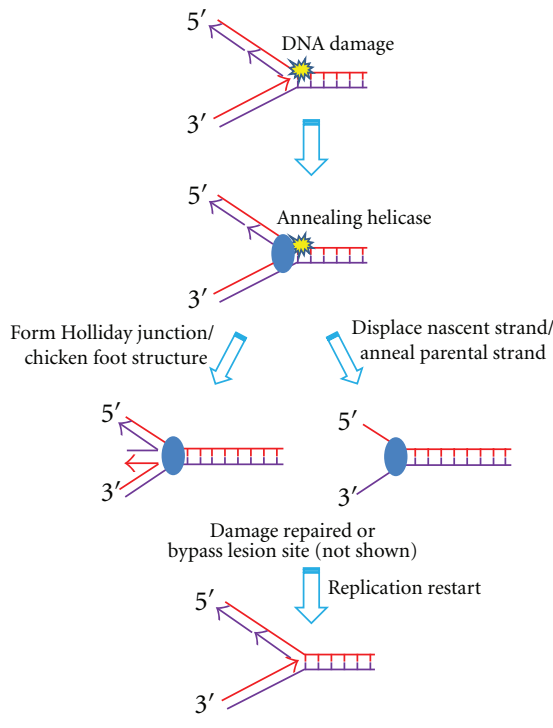

(a)

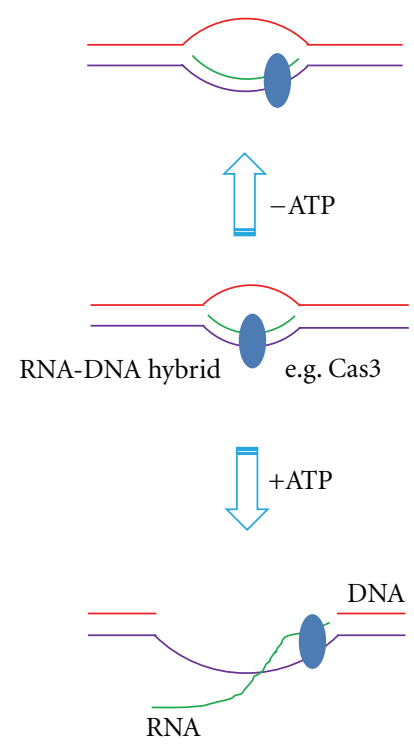

(c)

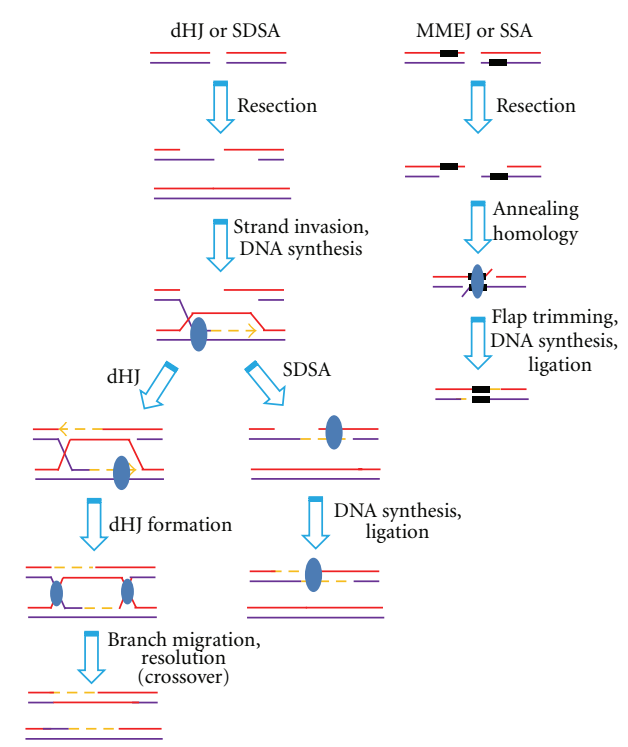

(b)

T-loop formation

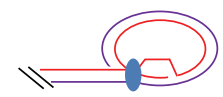

Telomere-SCE

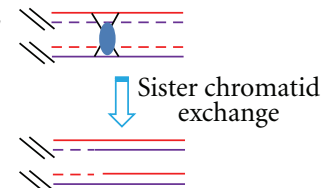

HR-dependent replication

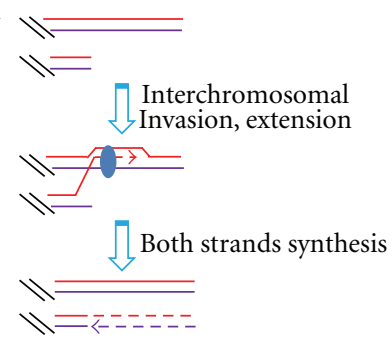

(d)

FIgURE 3: Purposed model of annealing helicase function in DNA replication, DNA repair, transcription, and telomere metabolism. (a) The annealing helicases function at stalled replication forks by catalyzing fork regression through Holliday junction migration (left) or displacing nascent strands and annealing parental strands (right). The replication fork proceeds until the DNA damage is repaired or bypassed. (b) Annealing helicases function in double-stranded DNA break repair. Annealing helicases might participate in homologous recombination repair through double Holliday junction $(\mathrm{dHJ})$ or synthesis-dependent strand annealing (SDSA) pathways (left) or microhomologymediated end joining (MMEJ) or single strand annealing (SSA) pathways (right). Noncrossover (uncommon) of dHJ is not shown. (c) Annealing helicases stabilize the DNA-RNA hybrid in transcription. Cas3 promotes RNA annealing to dsDNA without ATP and unwinding RNA from dsDNA with ATP. Model is adapted by analogy from one proposed for E. coli Cas3 helicase [89]. (d) Involvement of annealing helicases in telomere maintenance. Annealing helicases may catalyze the formation of T-loop structure or sister chromatid exchange and homologous recombination-dependent DNA replication in ALT cells. See text for details.

[118] and camptothecin (CPT) [100]. The MEFs derived from Recq5-deficient mice are hypersensitive to CPT [119]. In addition, it has been reported that both BLM and WRN are recruited to blocked replication forks in vivo [120] and can catalyze fork regression in vitro $[120,121]$. Moreover, the Orren lab recently demonstrated that WRN and BLM reestablish functional replication forks to overcome fork blockage [122]. All these evidence suggest that RecQ helicase, particularly BLM and WRN, participate in remodeling of stalled replication forks. However, it remains unknown how these helicases exert their annealing activity to contribute to replication fork restart. 
In addition to the RecQ helicases, human Pif1 helicase specifically recognizes and unwinds DNA structures resembling putative stalled replication forks [66]. Using yeast ribosomal DNA as a DNA replication model, it has been shown that the events of replication fork block are increased in Dna2 mutants [123]. In particular, Dna2 is involved in Okazaki fragment processing [72], and it will be of interest to determine if its annealing activity stabilizes the lagging strand. Unlike HARP and AH2, it would seem most likely that proteins with both unwinding and annealing activities might coordinate those activities to catalyze strand exchange and/or branch migration, such as generating and migrating a Holliday junction or chicken foot structure for stalled DNA replication forks (Figure 3(a)).

6.2. DNA Repair. The function of the RecQ helicase family in DNA repair processes is well recognized [6]. DNA2 helicase/endonuclease is directly implicated in Rad51-dependent recombinational repair [124]. The CSB protein is known to function in transcription-coupled DNA repair (TCR) [73]. The Pif1 helicase plays critical roles in both nuclear and mitochondrial genome stability [71]. HARP is localized to DSB sites [80]. Cells with HARP depletion display a higher frequency of DSB $[13,81]$ and sensitivity to DNA-damage (e.g., IR, MMC, and CPT) [12]. HARP is phosphorylated by ATM, ATR, and DNA-PK in vitro, and the mobility of HARP in SDS gels is altered when it is isolated from cells treated with DNA damage (HU, IR, and UV radiation) [11]. Taken together, evidence suggested that annealing helicases are involved in DNA repair, but the question remains how the annealing activity contributes to DNA repair processes.

Of the various types of DNA damage, DSB may be the most common and cytotoxic to cells. DSBs are repaired by Non-Homologous End Joining (NHEJ), Homologous Recombination (HR), and Microhomology-Mediated End Joining (MMEJ) [125]. All three DNA repair pathways need pairing of complementary single-stranded DNA, particularly HR and MMEJ. There are mainly four forms of HR in higher eukaryotic cells: double Holliday junctions $(\mathrm{dHJ})$ formed through crossover, synthesis-dependent strand annealing (SDSA) utilized by non-crossover, single-strand annealing (SSA) pathway between two repeat sequences, and breakinduced replication (BIR) pathway that repairs "one-ended" DSBs. Both crossover and noncrossover HR pathways are initiated by Rad 51 that searches and invades base-paired strands of homologous DNA molecules, then D-loop and HJs are formed consequently (Figure 3(b), left). RecQ helicases have strand exchange activity $[51,126]$ and HJs branch migration ability $[120,121]$. In the $\mathrm{dHJ}$ pathway, it is very likely that the RecQ helicases, particularly WRN and BLM, coordinate their unwinding and annealing activities to separate intact doublestranded DNA and pair invading strand to template in the early stage, migrate HJs, and finally help to cleave HJs. SDSA is a mechanism in which homology-mediated repair of DSBs occurs without formation and resolution of ligated HJs; it anneals the newly synthesized strand with the single strand resulting from resection of the second end (Figure 3(b), left). MMEJ or SSA use microhomologous sequences (5-25 bp) or long homologies (>30 bp) to align broken ends before ligation (Figure 3(b), right) [127]. Nevertheless, dHJ, SDSA, MMEJ, and SSA pathways heavily rely on single-strand DNAannealing activity driven by proteins. On the other hand, DNA helicases are recognized to play negative regulatory roles in recombination/repair through antirecombination, by disrupting presynaptic filaments prior to strand invasion, or by resolving D-loops before they can be extended and converted into replication forks. Although annealing helicases HARP and AH2 have not been investigated in the DNA repair pathways discussed above, both RECQ4 and BLM helicases are reported to be required to promote SDSA $[128,129]$. In the MMEJ or SSA pathways, nuclease activity is required in the flap-trimming step (Figure 3(b), right). In fact, it has been reported that several helicases, including annealing activity containing helicase RECQ5 $\beta$ [130], BLM [131], and WRN [132], stimulate cleavage activity of Flap endonuclease 1 (FEN-1).

6.3. Transcription. Besides their function in DNA replication and repair, another function of annealing helicases might be in DNA transcription (Figure 3(c)). Cas3 is a superfamily 2 helicase that possesses ATPase, helicase, and nuclease activities as evident in the Cas3 protein of Streptococcus thermophilus [133]. Recently, the E. coli Cas3 protein was found to promote R-loop (RNA:DNA hybrid) formation within duplex DNA in the absence of ATP and to disassemble R-loops in the presence of ATP [89], which is more relevant to structures formed in DNA transcription. It remains unknown whether such annealing helicase is present in human. Given the fact that the CSB protein is recruited to the site of a chromatin bound UV-stalled RNA polymerase II complex [134] and that the RECQ5 helicase physically and functionally associates with RNA polymerase II [135-138], it will be of interest to determine if the CSB and RECQ5 use their annealing activity to stabilize the transcription machine as a DNA damage response.

6.4. Telomere Metabolism. A number of RecQ helicases are implicated in telomere metabolism, including WRN [139], BLM [140], and RECQ4 [141]. Helicases Dna2 and Pif1 have also been implicated in chromosome end stability [142]. The purified recombinant PIF1 proteins bind telomeric DNA with a 100-fold higher affinity compared to random sequence, and telomere shortening was observed when PIF1 was overexpressed [143]. Telomere effects of Dna2 proteins have been reported in $S$. cerevisiae and $S$. pombe [144, 145]. It will be of interest to know how these helicases exert their strand annealing activity, in particular RECQ4 that has robust annealing activity, to function in telomere maintenance. Annealing helicases might participate in telomere metabolism, where single strand overhang could require an annealing helicase to form a more stable structure, such as T-loop (Figure 3(d)). For cells which operated by the Alternative Lengthening of Telomere (ALT) pathway, it is possible that strand annealing/strand exchange catalyzed by certain RecQ helicases may participate in telomere-sister chromatid exchange and HR-dependent DNA replication (Figure 3(d)). Coordination of strand annealing and unwinding activity at 
the G-rich telomeric end may influence telomere stability by affecting DNA replication and repair processes, such as resolving G4 DNA.

6.5. Chromatin Remodeling. HARP and AH2 belong to Swi2/Snf2 family that has been considered chromatin remodeling enzymes. The characteristic feature of this class of enzymes is that they contain a conserved ATPase domain with the seven classic helicase-related motifs. The Swi2/Snf2 ATPases are grouped within the SF2 helicase superfamily, and they have a distinct primary sequence signature defined by the spacing between helicase motifs III and IV as well as conserved features of their sequences within the domain [146]. Although most Swi2/Snf2 ATPases do not have duplex DNA strand separating activity, they retain other features of helicases, including directional DNA translocation fueled by ATP hydrolysis, participation in chromatin structure modeling, regulation transcription, and DNA repair.

Unlike HARP and AH2, not all helicase domains containing Snf2 family proteins have annealing activity, but like HARP and AH2, many of them have been identified to promote branch migration of HJs in an ATP hydrolysis-dependent manner. In prokaryotes, RuvAB and RecG have been shown to promote branch migration of HJs [147, 148]. In eukaryotes, several members of Snf2 can promote fork regression and/or branch migration of $\mathrm{HJs}$, including Rad54 [149], Rad5 [150, 151], and HLTF [152]. CHD7, a helicase domain containing Snf2 protein accounted for the majority of CHARGE syndrome, plays a role in transcription regulation by chromatin remodeling [153]. Although FANCM is not a Snf2 family member, it consists of an N-terminal SF2 helicase domain and a C-terminal inactive endonuclease domain. FANCM is able to branch migrate HJs and replication forks in vitro [154, 155]. Very recently, several helicase domain containing Snf2 proteins, including SMARCA2 and SMARCA4, were identified to cause Nicolaides-Baraitser syndrome [156] and Coffin-Siris syndrome [157]. Interestingly, most of the patient mutations are located in the helicase domain, suggesting its importance for their function. However, it remains unknown whether they have strand annealing activity in vitro. In conclusion, it is a growing family of proteins that contain ATPase/helicase domain, which use their enzymatic activity to regulate chromatin structure and gene expression.

\section{Conclusions and Perspectives}

The discovery of annealing helicases establishes the presence of a class of enzymes that possess only rewinding activity and opens a new area of research. The range of proteins that function as annealing helicases remains to be determined. Researchers now hope to determine the biological function of HARP and AH2 more fully, as well as to discover more of these types of enzymes. Annealing helicases could also potentially be found for RNA-DNA and RNA-RNA hybrids, expanding the research into areas such as protein synthesis, RNA stability, and gene silencing. There is no doubt that more and more annealing helicases will be identified. The coordinated action of unwinding and annealing may play a role in fork regression or synthesis-dependent strand annealing, in the pathway for DSB repair, as well as in transcription and telomere metabolism. The challenge will then be to understand how cells regulate helicase unwinding and rewinding activity in vivo, and determine where or when the annealing activity of helicase is needed. From an experimental standpoint, it would be great interest to identify and characterize separation of function mutants which: (1) inactivate helicase activity but retain strand annealing; (2) inactivate strand annealing but retain helicase activity. Characterization of clinically relevant or engineered helicase core domain and auxiliary domain missense mutants may be valuable to determine which biological pathways/steps require strand annealing versus unwinding activity. Finally, a better understanding of the biological function of annealing helicases is likely to provide the basis for treating a variety of human disorders, such as SIOD of HARP, premature aging of RecQ helicases, and cancers.
Abbreviations
ssDNA: Single-stranded DNA
ssRNA: Single-stranded RNA
dsDNA: Double-stranded DNA
HARP: HepA-related protein
SIOD: Schimke immunoosseous dysplasia
AH2: Annealing helicase 2
DSB: Double-strand break
NHEJ: Non-homologous end joining
HR: Homologous recombination
MMEJ: Microhomology-mediated end joining
SDSA: Synthesis-dependent strand annealing
SSA: $\quad$ Single strand annealing
HJ: Holliday junction
ALT: Alternative lengthening of telomere.

\section{Acknowledgments}

The author's laboratory is supported by the Saskatchewan Health Research Foundation (SHRF) and the Natural Sciences and Engineering Research Council of Canada (NSERC). The author would like to thank Drs. Robert Brosh (National Institute on Aging-NIH) and Stanley Moore (Department of Biochemistry, University of Saskatchewan) for critical reading and comments on the paper.

\section{References}

[1] T. M. Lohman and K. P. Bjornson, "Mechanisms of helicasecatalyzed DNA unwinding," Annual Review of Biochemistry, vol. 65, pp. 169-214, 1996.

[2] M. R. Singleton, M. S. Dillingham, and D. B. Wigley, "Structure and mechanism of helicases and nucleic acid translocases," Annual Review of Biochemistry, vol. 76, pp. 2350, 2007.

[3] S. S. Patel and I. Donmez, "Mechanisms of helicases," Journal of Biological Chemistry, vol. 281, no. 27, pp. 18265-18268, 2006. 
[4] R. M. Brosh Jr. and V. A. Bohr, "Human premature aging, DNA repair and RecQ helicases," Nucleic Acids Research, vol. 35, no. 22, pp. 7527-7544, 2007.

[5] M. S. Dillingham, "Superfamily I helicases as modular components of DNA-processing machines," Biochemical Society Transactions, vol. 39, no. 2, pp. 413-423, 2011.

[6] K. A. Bernstein, S. Gangloff, and R. Rothstein, "The RecQ DNA helicases in DNA repair," Annual Review of Genetics, vol. 44, pp. 393-417, 2010.

[7] E. Jankowsky, "RNA helicases at work: binding and rearranging," Trends in Biochemical Sciences, vol. 36, no. 1, pp. 19-29, 2011.

[8] A. M. Pyle, "Translocation and unwinding mechanisms of RNA and DNA helicases," Annual Review of Biophysics, vol. 37, pp. 317-336, 2008.

[9] D. K. Singh, A. K. Ghosh, D. L. Croteau, and V. A. Bohr, "RecQ helicases in DNA double strand break repair and telomere maintenance," Mutation Research. In press.

[10] Y. Wu, A. N. Suhasini, and R. M. Brosh Jr., "Welcome the family of FANCJ-like helicases to the block of genome stability maintenance proteins," Cellular and Molecular Life Sciences, vol. 66, no. 7, pp. 1209-1222, 2009.

[11] C. E. Bansbach, R. Bétous, C. A. Lovejoy, G. G. Glick, and D. Cortez, "The annealing helicase SMARCAL1 maintains genome integrity at stalled replication forks," Genes and Development, vol. 23, no. 20, pp. 2405-2414, 2009.

[12] A. Ciccia, A. L. Bredemeyer, M. E. Sowa et al., "The SIOD disorder protein SMARCAL1 is an RPA-interacting protein involved in replication fork restart," Genes and Development, vol. 23, no. 20, pp. 2415-2425, 2009.

[13] J. Yuan, G. Ghosal, and J. Chen, "The annealing helicase HARP protects stalled replication forks," Genes and Development, vol. 23, no. 20, pp. 2394-2399, 2009.

[14] T. Yusufzai and J. T. Kadonaga, "HARP is an ATP-driven annealing helicase," Science, vol. 322, no. 5902, pp. 748-750, 2008.

[15] T. Yusufzai and J. T. Kadonaga, "Annealing helicase 2 (AH2), a DNA-rewinding motor with an $\mathrm{HNH}$ motif," Proceedings of the National Academy of Sciences of the United States of America, vol. 107, no. 49, pp. 20970-20973, 2010.

[16] G. M. Weinstock, K. McEntee, and I. R. Lehman, "ATPdependent renaturation of DNA catalyzed by the recA protein of Escherichia coli," Proceedings of the National Academy of Sciences of the United States of America, vol. 76, no. 1, pp. 126-130, 1979.

[17] S. L. Keener and K. Mcentee, "Homologous pairing of singlestranded circular DNAs catalyzed by recA protein," Nucleic Acids Research, vol. 12, no. 15, pp. 6127-6139, 1984.

[18] B. Muller and A. Stasiak, "RecA-mediated annealing of single-stranded DNA and its relation to the mechanism of homologous recombination," Journal of Molecular Biology, vol. 221, no. 1, pp. 131-145, 1991.

[19] D. P. Kirkpatrick, B. J. Rao, and C. M. Radding, "RNA-DNA hybridization promoted by E.Coli RecA protein," Nucleic Acids Research, vol. 20, no. 16, pp. 4339-4346, 1992.

[20] M. E. Cusick and M. Belfort, "Domain structure and RNA annealing activity of the Escherichia coli regulatory protein StpA," Molecular Microbiology, vol. 28, no. 4, pp. 847-857, 1998.

[21] N. Kantake, M. V. V. M. Madiraju, T. Sugiyama, and S. C. Kowalczykowski, "Escherichia coli RecO protein anneals ssDNA complexed with its cognate ssDNA-binding protein: a common step in genetic recombination," Proceedings of the National Academy of Sciences of the United States of America, vol. 99, no. 24, pp. 15327-15332, 2002.
[22] Z. Zuo, H. K. Lin, and M. A. Trakselis, "Strand annealing and terminal transferase activities of a B-family DNA polymerase," Biochemistry, vol. 50, no. 23, pp. 5379-5390, 2011.

[23] U. H. Mortensen, C. Bendixen, I. Sunjevaric, and R. Rothstein, "DNA strand annealing is promoted by the yeast RaD52 protein," Proceedings of the National Academy of Sciences of the United States of America, vol. 93, no. 20, pp. 10729-10734, 1996.

[24] Y. Wu, N. Kantake, T. Sugiyama, and S. C. Kowalczykowski, "Rad51 protein controls Rad52-mediated DNA annealing," Journal of Biological Chemistry, vol. 283, no. 21, pp. 1488314892, 2008.

[25] Y. Wu, T. Sugiyama, and S. C. Kowalczykowski, "DNA annealing mediated by Rad52 and Rad59 proteins," Journal of Biological Chemistry, vol. 281, no. 22, pp. 15441-15449, 2006.

[26] T. Sugiyama, J. H. New, and S. C. Kowalczykowski, "DNA annealing by Rad52 protein is stimulated by specific interaction with the complex of replication protein A and singlestranded DNA," Proceedings of the National Academy of Sciences of the United States of America, vol. 95, no. 11, pp. 6049-6054, 1998.

[27] N. Sugawara, G. Ira, and J. E. Haber, "DNA length dependence of the single-strand annealing pathway and the role of Saccharomyces cerevisiae RAD59 in double-strand break repair," Molecular and Cellular Biology, vol. 20, no. 14, pp. 5300-5309, 2000.

[28] A. P. Davis and L. S. Symington, "The yeast recombinational repair protein Rad59 interacts with Rad52 and stimulates single-strand annealing," Genetics, vol. 159, no. 2, pp. 515525, 2001.

[29] E. Hitti, A. Neunteufl, and M. F. Jantsch, "The doublestranded RNA-binding protein Xlrbpa promotes RNA strand annealing," Nucleic Acids Research, vol. 26, no. 19, pp. 43824388,1998

[30] M. Kuciak, C. Gabus, R. Ivanyi-Nagy et al., "The HIV1 transcriptional activator Tat has potent nucleic acid chaperoning activities in vitro," Nucleic Acids Research, vol. 36, no. 10, pp. 3389-3400, 2008.

[31] C. Boudier, R. Storchak, K. K. Sharma et al., "The mechanism of HIV-1 Tat-directed nucleic acid annealing supports its role in reverse transcription," Journal of Molecular Biology, vol. 400, no. 3, pp. 487-501, 2010.

[32] W. L. Pong, Z. S. Huang, P. G. Teoh, C. C. Wang, and H. N. $\mathrm{Wu}$, "RNA binding property and RNA chaperone activity of dengue virus core protein and other viral RNA-interacting proteins," FEBS Letters, vol. 585, pp. 2575-2581, 2011.

[33] A. Kumar and S. H. Wilson, "Studies of the strandannealing activity of mammalian hnRNP complex protein A1," Biochemistry, vol. 29, no. 48, pp. 10717-10722, 1990.

[34] F. Cobianchi, C. Calvio, M. Stoppini, M. Buvoli, and S. Riva, "Phosphorylation of human hnRNP protein Al abrogates in vitro strand annealing activity," Nucleic Acids Research, vol. 21, no. 4, pp. 949-955, 1993.

[35] H. Idriss, A. Kumar, J. R. Casas-Finet, H. Guo, Z. Damuni, and S. H. Wilson, "Regulation of in vitro nucleic acid strand annealing activity of heterogeneous nuclear ribonucleoprotein protein A1 by reversible phosphorylation," Biochemistry, vol. 33, no. 37, pp. 11382-11390, 1994.

[36] H. W. Sturzbecher, R. Brain, T. Maimets, C. Addison, K. Rudge, and J. R. Jenkins, "Mouse p53 blocks SV40 DNA replication in vitro and downregulates $\mathrm{T}$ antigen DNA helicase activity," Oncogene, vol. 3, no. 4, pp. 405-413, 1988.

[37] P. Oberosler, P. Hloch, U. Ramsperger, and H. Stahl, "p53-catalyzed annealing of complementary single-stranded 
nucleic acids," EMBO Journal, vol. 12, no. 6, pp. 2389-2396, 1993.

[38] M. de Jager, M. L. G. Dronkert, M. Modesti, C. E. M. T. Beerens, R. Kanaar, and D. C. van Gent, "DNA-binding and strand-annealing activities of human Mre11: implications for its roles in DNA double-strand break repair pathways," Nucleic Acids Research, vol. 29, no. 6, pp. 1317-1325, 2001.

[39] H. Yokoyama, N. Sarai, W. Kagawa et al., "Preferential binding to branched DNA strands and strand-annealing activity of the human Rad51B, Rad51C, Rad51D and Xrcc2 protein complex," Nucleic Acids Research, vol. 32, no. 8, pp. 2556-2565, 2004.

[40] B. C. Valdez, D. Henning, K. Perumal, and H. Busch, "RNAunwinding and RNA-folding activities of RNA helicase II/Gu-two activities in separate domains of the same protein," European Journal of Biochemistry, vol. 250, no. 3, pp. 800-807, 1997.

[41] O. G. Rössler, A. Straka, and H. Stahl, "Rearrangement of structured RNA via branch migration structures catalysed by the highly related DEAD-box proteins p68 and p72," Nucleic Acids Research, vol. 29, no. 10, pp. 2088-2096, 2001.

[42] H. Uhlmann-Schiffler, C. Jalal, and H. Stahl, "Ddx42p-a human DEAD box protein with RNA chaperone activities," Nucleic Acids Research, vol. 34, no. 1, pp. 10-22, 2006.

[43] S. Zhang and F. Grosse, "Multiple functions of nuclear DNA Helicase II (RNA helicase A) in nucleic acid metabolism," Acta Biochimica et Biophysica Sinica, vol. 36, no. 3, pp. 177183, 2004.

[44] L. Xing, C. Liang, and L. Kleiman, "Coordinate roles of gag and RNA helicase A in promoting the annealing of tRNA3Lysto HIV-1 RNA," Journal of Virology, vol. 85, no. 4, pp. 1847-1860, 2011.

[45] Q. Yang and E. Jankowsky, "ATP- and ADP-dependent modulation of RNA unwinding and strand annealing activities by the DEAD-box protein DED1," Biochemistry, vol. 44, no. 41, pp. 13591-13601, 2005.

[46] C. Halls, S. Mohr, M. del Campo, Q. Yang, E. Jankowsky, and A. M. Lambowitz, "Involvement of DEAD-box proteins in group I and group II intron splicing. Biochemical characterization of Mss116p, ATP hydrolysis-dependent and -independent mechanisms, and general RNA chaperone activity," Journal of Molecular Biology, vol. 365, no. 3, pp. 835855, 2007.

[47] B. Chamot, K. R. Colvin, S. L. Kujat-Choy, and G. W. Owttrim, "RNA structural rearrangement via unwinding and annealing by the cyanobacterial RNA helicase, CrhR," Journal of Biological Chemistry, vol. 280, no. 3, pp. 2036-2044, 2005.

[48] L. G. Gebhard, S. B. Kaufman, and A. V. Gamarnik, "Novel ATP-independent RNA annealing activity of the dengue virus NS3 helicase," PLoS One, vol. 7, no. 4, article e36244, 2012.

[49] S. Sharma, J. A. Sommers, S. Choudhary et al., "Biochemical analysis of the DNA unwinding and strand annealing activities catalyzed by human RECQ1," Journal of Biological Chemistry, vol. 280, no. 30, pp. 28072-28084, 2005.

[50] L. Muzzolini, F. Beuron, A. Patwardhan et al., "Different quaternary structures of human RECQ1 are associated with its dual enzymatic activity," PLoS Biology, vol. 5, no. 2, article e20, 2007.

[51] A. Machwe, L. Xiao, J. Groden, S. W. Matson, and D. K. Orren, "RecQ family members combine strand pairing and unwinding activities to catalyze strand exchange," Journal of Biological Chemistry, vol. 280, no. 24, pp. 23397-23407, 2005.

[52] M. Muftuoglu, T. Kulikowicz, G. Beck, J. W. Lee, J. Piotrowski, and V. A. Bohr, "Intrinsic ssDNA annealing activity in the C-terminal region of WRN," Biochemistry, vol. 47, no. 39, pp. 10247-10254, 2008.

[53] C. F. Cheok, L. Wu, P. L. Garcia, P. Janscak, and I. D. Hickson, "The Bloom's syndrome helicase promotes the annealing of complementary single-stranded DNA," Nucleic Acids Research, vol. 33, no. 12, pp. 3932-3941, 2005.

[54] X. Xu and Y. Liu, "Dual DNA unwinding activities of the Rothmund-Thomson syndrome protein, RECQ4," EMBO Journal, vol. 28, no. 5, pp. 568-577, 2009.

[55] P. L. Garcia, Y. Liu, J. Jiricny, S. C. West, and P. Janscak, "Human RECQ51 $\beta$, a protein with DNA helicase and strandannealing activities in a single polypeptide," EMBO Journal, vol. 23, no. 14, pp. 2882-2891, 2004.

[56] Y. Gu, Y. Masuda, and K. Kamiya, "Biochemical analysis of human PIF1 helicase and functions of its N-terminal domain," Nucleic Acids Research, vol. 36, no. 19, pp. 62956308, 2008.

[57] T. Masuda-Sasa, P. Polaczek, and J. L. Campbell, "Single strand annealing and ATP-independent strand exchange activities of yeast and human DNA2: possible role in okazaki fragment maturation," Journal of Biological Chemistry, vol. 281, no. 50, pp. 38555-38564, 2006.

[58] M. Muftuoglu, S. Sharma, T. Thorslund et al., "Cockayne syndrome group B protein has novel strand annealing and exchange activities," Nucleic Acids Research, vol. 34, no. 1, pp. 295-304, 2006.

[59] D. Sen, D. Nandakumar, G. Q. Tang, and S. S. Patel, "The Human Mitochondrial DNA helicase TWINKLE is both an unwinding and an annealing helicase," The Journal of Biological Chemistry, vol. 287, pp. 14545-14556, 2012.

[60] Y. Hu, X. Lu, E. Barnes, M. Yan, H. Lou, and G. Luo, "Recql5 and Blm RecQ DNA helicases have nonredundant roles in suppressing crossovers," Molecular and Cellular Biology, vol. 25, no. 9, pp. 3431-3442, 2005.

[61] Y. Hu, S. Raynard, M. G. Sehorn et al., "RECQL5/Recql5 helicase regulates homologous recombination and suppresses tumor formation via disruption of Rad51 presynaptic filaments," Genes and Development, vol. 21, no. 23, pp. 30733084, 2007.

[62] D. Li, H. Liu, L. Jiao et al., "Significant effect of homologous recombination DNA repair gene polymorphisms on pancreatic cancer survival," Cancer Research, vol. 66, no. 6, pp. 3323-3330, 2006.

[63] D. Li, M. Frazier, D. B. Evans et al., "Single nucleotide polymorphisms of RecQ1, RAD54L, and ATM genes are associated with reduced survival of pancreatic cancer," Journal of Clinical Oncology, vol. 24, no. 11, pp. 1720-1728, 2006.

[64] C. F. Chen and S. J. Brill, "An essential DNA strand-exchange activity is conserved in the divergent N-termini of BLM orthologs," EMBO Journal, vol. 29, no. 10, pp. 1713-1725, 2010.

[65] B. T. Weinert and D. C. Rio, "DNA strand displacement, strand annealing and strand swapping by the Drosophila Bloom's syndrome helicase," Nucleic Acids Research, vol. 35, no. 4, pp. 1367-1376, 2007.

[66] T. George, Q. Wen, R. Griffiths, A. Ganesh, M. Meuth, and C. M. Sanders, "Human Pif1 helicase unwinds synthetic DNA structures resembling stalled DNA replication forks," Nucleic Acids Research, vol. 37, no. 19, pp. 6491-6502, 2009.

[67] J. Yin, Y. T. Kwon, A. Varshavsky, and W. Wang, "RECQL4, mutated in the Rothmund-Thomson and RAPADILINO syndromes, interacts with ubiquitin ligases UBR1 and UBR2 of the N-end rule pathway," Human Molecular Genetics, vol. 13, no. 20, pp. 2421-2430, 2004. 
[68] M. A. Macris, L. Krejci, W. Bussen, A. Shimamoto, and P. Sung, "Biochemical characterization of the RECQ4 protein, mutated in Rothmund-Thomson syndrome," DNA Repair, vol. 5, no. 2, pp. 172-180, 2006.

[69] T. Suzuki, T. Kohno, and Y. Ishimi, "DNA helicase activity in purified human RECQL4 protein," Journal of Biochemistry, vol. 146, no. 3, pp. 327-335, 2009.

[70] M. L. Rossi, A. K. Ghosh, T. Kulikowicz, D. L. Croteau, and V. A. Bohr, "Conserved helicase domain of human RecQ4 is required for strand annealing-independent DNA unwinding," DNA Repair, vol. 9, no. 7, pp. 796-804, 2010.

[71] M. L. Bochman, N. Sabouri, and V. A. Zakian, "Unwinding the functions of the Pif1 family helicases," DNA Repair, vol. 9, no. 3, pp. 237-249, 2010.

[72] Y. H. Kang, C. H. Lee, and Y. S. Seo, "Dna2 on the road to Okazaki fragment processing and genome stability in eukaryotes," Critical Reviews in Biochemistry and Molecular Biology, vol. 45, no. 2, pp. 71-96, 2010.

[73] V. Natale, "A comprehensive description of the severity groups in Cockayne syndrome," American Journal of Medical Genetics A, vol. 155, no. 5, pp. 1081-1095, 2011.

[74] S. W. Nelson and S. J. Benkovic, "The T4 phage UvsW protein contains both DNA unwinding and strand annealing activities," Journal of Biological Chemistry, vol. 282, no. 1, pp. 407-416, 2007.

[75] Z. Li, S. Lu, G. Hou et al., "Hjm/Hel308a DNA Helicase from Sulfolobus tokodaii promotes replication fork regression and interacts with $\mathrm{Hjc}$ endonuclease in vitro," Journal of Bacteriology, vol. 190, no. 8, pp. 3006-3017, 2008.

[76] M. de Felice, V. Aria, L. Esposito et al., "A novel DNA helicase with strand-annealing activity from the crenarchaeon sulfolobus solfataricus," Biochemical Journal, vol. 408, no. 1, pp. 87-95, 2007.

[77] S. V. Balasingham, E. D. Zegeye, H. Homberset et al., "Enzymatic activities and DNA substrate specificity of mycobacterium tuberculosis DNA helicase XPB," PLoS One, vol. 7, article e36960, 2012.

[78] C. F. Boerkoel, H. Takashima, J. John et al., "Mutant chromatin remodeling protein SMARCAL1 causes Schimke immuno-osseous dysplasia," Nature Genetics, vol. 30, no. 2, pp. 215-220, 2002.

[79] L. I. Elizonod, K. S. Cho, W. Zhang et al., "Schimke immunoosseous dysplasia: SMARCAL1 loss-of-function and phenotypic correlation," Journal of Medical Genetics, vol. 46, no. 1, pp. 49-59, 2009.

[80] T. Yusufzai, X. Kong, K. Yokomori, and J. T. Kadonaga, "The annealing helicase HARP is recruited to DNA repair sites via an interaction with RPA," Genes and Development, vol. 23, no. 20, pp. 2400-2404, 2009.

[81] L. Postow, E. M. Woo, B. T. Chait, and H. Funabiki, "Identification of SMARCAL1 as a component of the DNA damage response," Journal of Biological Chemistry, vol. 284, no. 51, pp. 35951-35961, 2009.

[82] G. Ghosal, J. Yuan, and J. Chen, "The HARP domain dictates the annealing helicase activity of HARP/SMARCAL1," EMBO Reports, vol. 12, no. 6, pp. 574-580, 2011.

[83] R. Betous, A. C. Mason, R. P. Rambo et al., "SMARCAL1 catalyzes fork regression and Holliday junction migration to maintain genome stability during DNA replication," Genes \& Development., vol. 26, pp. 151-162, 2012.

[84] A. Flaus, D. M. A. Martin, G. J. Barton, and T. OwenHughes, "Identification of multiple distinct Snf2 subfamilies with conserved structural motifs," Nucleic Acids Research, vol. 34, no. 10, pp. 2887-2905, 2006.
[85] B. L. Stoddard, "Homing endonuclease structure and function," Quarterly Reviews of Biophysics, vol. 38, no. 1, pp. 4995, 2005.

[86] R. B. Guo, P. Rigolet, H. Ren et al., "Structural and functional analyses of disease-causing missense mutations in Bloom syndrome protein," Nucleic Acids Research, vol. 35, no. 18, pp. 6297-6310, 2007.

[87] M. E. Fairman-Williams, U. P. Guenther, and E. Jankowsky, "SF1 and SF2 helicases: family matters," Current Opinion in Structural Biology, vol. 20, no. 3, pp. 313-324, 2010.

[88] B. Lucic, Y. Zhang, O. King et al., "A prominent $\beta$-hairpin structure in the winged-helix domain of RECQ1 is required for DNA unwinding and oligomer formation," Nucleic Acids Research, vol. 39, no. 5, pp. 1703-1717, 2011.

[89] J. L. Howard, S. Delmas, I. Ivancic-Bace, and E. L. Bolt, "Helicase dissociation and annealing of RNA-DNA hybrids by escherichia coli Cas3 protein," Biochemical Journal, vol. 439, pp. 85-95, 2011.

[90] E. Fanning, V. Klimovich, and A. R. Nager, "A dynamic model for replication protein A (RPA) function in DNA processing pathways," Nucleic Acids Research, vol. 34, no. 15, pp. 41264137, 2006.

[91] M. S. Wold, "Replication protein A: a heterotrimeric, singlestranded DNA-binding protein required for eukaryotic DNA metabolism," Annual Review of Biochemistry, vol. 66, pp. 6192, 1997.

[92] R. M. Brosh Jr., D. K. Orren, J. O. Nehlin et al., "Functional and physical interaction between WRN helicase and human replication protein A," Journal of Biological Chemistry, vol. 274, no. 26, pp. 18341-18350, 1999.

[93] J. C. Shen, M. D. Gray, J. Oshima, and L. A. Loeb, "Characterization of Werner syndrome protein DNA helicase activity: directionality, substrate dependence and stimulation by replication protein A," Nucleic Acids Research, vol. 26, no. 12, pp. 2879-2885, 1998.

[94] R. M. Brosh Jr., J. L. Li, M. K. Kenny et al., "Replication protein a physically interacts with the Bloom's syndrome protein and stimulates its helicase activity," Journal of Biological Chemistry, vol. 275, no. 31, pp. 23500-23508, 2000.

[95] S. Cui, D. Arosio, K. M. Doherty, R. M. Brosh Jr., A. Falaschi, and A. Vindigni, "Analysis of the unwinding activity of the dimeric RECQ1 helicase in the presence of human replication protein A," Nucleic Acids Research, vol. 32, no. 7, pp. 2158-2170, 2004.

[96] R. Gupta, S. Sharma, J. A. Sommers, M. K. Kenny, S. B. Cantor, and R. M. Brosh Jr., "FANCJ (BACH1) helicase forms DNA damage inducible foci with replication protein a and interacts physically and functionally with the single-stranded DNA-binding protein," Blood, vol. 110, no. 7, pp. 2390-2398, 2007.

[97] H. Yan, T. Toczylowski, J. McCane, C. Chen, and S. Liao, "Replication protein A promotes 5' $\rightarrow 3^{\prime}$ end processing during homology-dependent DNA double-strand break repair," Journal of Cell Biology, vol. 192, no. 2, pp. 251-261, 2011.

[98] C. G. Lee, P. D. Zamore, M. R. Green, and J. Hurwitz, "RNA annealing activity is intrinsically associated with U2AF," Journal of Biological Chemistry, vol. 268, no. 18, pp. 1347213478, 1993.

[99] K. S. Trego, S. B. Chernikova, A. R. Davalos et al., "The DNA repair endonuclease XPG interacts directly and functionally with the WRN helicase defective in Werner syndrome," Cell Cycle, vol. 10, no. 12, pp. 1998-2007, 2011.

[100] S. Sharma and R. M. Brosh Jr., "Human RECQ1 is a DNA damage responsive protein required for genotoxic stress 
resistance and suppression of sister chromatid exchanges," PLoS ONE, vol. 2, no. 12, article e1297, 2007.

[101] M. Ababou, S. Dutertre, Y. Lécluse, R. Onclercq, B. Chatton, and M. Amor-Guéret, "ATM-dependent phosphorylation and accumulation of endogenous BLM protein in response to ionizing radiation," Oncogene, vol. 19, no. 52, pp. 5955$5963,2000$.

[102] H. Beamish, P. Kedar, H. Kaneko et al., "Functional link between BLM defective in Bloom's syndrome and the ataxiatelangiectasia-mutated protein, ATM," Journal of Biological Chemistry, vol. 277, no. 34, pp. 30515-30523, 2002.

[103] S. L. Davies, P. S. North, A. Dart, N. D. Lakin, and I. D. Hickson, "Phosphorylation of the bloom's syndrome helicase and its role in recovery from S-phase arrest," Molecular and Cellular Biology, vol. 24, no. 3, pp. 1279-1291, 2004.

[104] S. Sengupta, A. I. Robles, S. P. Linke et al., "Functional interaction between BLM helicase and 53BP1 in a Chk1mediated pathway during S-phase arrest," Journal of Cell Biology, vol. 166, no. 6, pp. 801-813, 2004.

[105] E. Bayart, S. Dutertre, C. Jaulin, R. B. Guo, G. X. Xu, and M. Amor-Guéret, "The bloom syndrome helicase is a substrate of the mitotic Cdc2 kinase," Cell Cycle, vol. 5, no. 15, pp. 1681-1686, 2006.

[106] M. Leng, D. W. Chan, H. Luo, C. Zhu, J. Qin, and Y. Wang, "MPS1-dependent mitotic BLM phosphorylation is important for chromosome stability," Proceedings of the National Academy of Sciences of the United States of America, vol. 103, no. 31, pp. 11485-11490, 2006.

[107] P. Pichierri, F. Rosselli, and A. Franchitto, "Werner's syndrome protein is phosphorylated in an ATR/ATM-dependent manner following replication arrest and DNA damage induced during the $\mathrm{S}$ phase of the cell cycle," Oncogene, vol. 22, no. 10, pp. 1491-1500, 2003.

[108] F. Ammazzalorso, L. M. Pirzio, M. Bignami, A. Franchitto, and P. Pichierri, "ATR and ATM differently regulate WRN to prevent DSBs at stalled replication forks and promote replication fork recovery," EMBO Journal, vol. 29, no. 18, pp. 3156-3169, 2010.

[109] S. Eladad, T. Z. Ye, P. Hu et al., "Intra-nuclear trafficking of the BLM helicase to DNA damage-induced foci is regulated by SUMO modification," Human Molecular Genetics, vol. 14, no. 10, pp. 1351-1365, 2005.

[110] G. Blandert, N. Zalle, Y. Daniely, J. Taplick, M. D. Gray, and M. Oren, "DNA damage-induced translocation of the werner helicase is regulated by acetylation," Journal of Biological Chemistry, vol. 277, no. 52, pp. 50934-50940, 2002.

[111] J. M. Clewing, H. Fryssira, D. Goodman et al., "Schimke immunoosseous dysplasia: suggestions of genetic diversity," Human Mutation, vol. 28, no. 3, pp. 273-283, 2007.

[112] R. Driscoll and K. A. Cimprich, "HARPing on about the DNA damage response during replication," Genes and Development, vol. 23, no. 20, pp. 2359-2365, 2009.

[113] L. Wu and I. D. Hickson, "DNA helicases required for homologous recombination and repair of damaged replication forks," Annual Review of Genetics, vol. 40, pp. 279-306, 2006.

[114] K. K. Dhillon, J. Sidorova, Y. Saintigny et al., "Functional role of the Werner syndrome RecQ helicase in human fibroblasts," Aging Cell, vol. 6, no. 1, pp. 53-61, 2007.

[115] M. Poot, J. S. Yom, S. H. Whang, J. T. Kato, K. A. Gollahon, and P. S. Rabinovitch, "Werner syndrome cells are sensitive to DNA cross-linking drugs," The FASEB Journal, vol. 15, no. 7, pp. 1224-1226, 2001.

[116] G. J. Hook, E. Kwok, and J. A. Heddle, "Sensitivity of Bloom syndrome fibroblasts to mitomycin C," Mutation Research, vol. 131, no. 5-6, pp. 223-230, 1984.
[117] W. Jin, H. Liu, Y. Zhang, S. K. Otta, S. E. Plon, and L. L. Wang, "Sensitivity of RECQL4-deficient fibroblasts from Rothmund-Thomson syndrome patients to genotoxic agents," Human Genetics, vol. 123, no. 6, pp. 643-653, 2008.

[118] R. Mendoza-Maldonado, V. Faoro, S. Bajpai et al., "The human RECQ1 helicase is highly expressed in glioblastoma and plays an important role in tumor cell proliferation," Molecular Cancer, vol. 10, article 83, 2011.

[119] Y. Hu, X. Lu, G. Zhou, E. L. Barnes, and G. Luo, "Recql5 plays an important role in DNA replication and cell survival after camptothecin treatment," Molecular Biology of the Cell, vol. 20, no. 1, pp. 114-123, 2009.

[120] A. Constantinou, M. Tarsounas, J. K. Karow et al., "Werner's syndrome protein (WRN) migrates Holliday junctions and co-localizes with RPA upon replication arrest," EMBO Reports, vol. 1, no. 1, pp. 80-84, 2000.

[121] J. K. Karow, A. Constantinou, J. L. Li, S. C. West, and I. D. Hickson, "The Bloom's syndrome gene product promotes branch migration of Holliday junctions," Proceedings of the National Academy of Sciences of the United States of America, vol. 97, no. 12, pp. 6504-6508, 2000.

[122] A. Machwe, R. Karale, X. Xu, Y. Liu, and D. K. Orren, “The Werner and Bloom syndrome proteins help resolve replication blockage by converting (regressed) holliday junctions to functional replication forks," Biochemistry, vol. 50, pp. 67746788, 2011.

[123] T. Weitao, M. Budd, L. L. M. Hoopes, and J. L. Campbell, "Dna2 helicase/nuclease causes replicative fork stalling and double-strand breaks in the ribosomal DNA of saccharomyces cerevisiae," Journal of Biological Chemistry, vol. 278, no. 25, pp. 22513-22522, 2003.

[124] M. E. Budd and J. L. Campbell, "Interplay of Mre11 nuclease with Dna2 plus Sgs1 in Rad51-dependent recombinational repair," PLoS ONE, vol. 4, no. 1, article e4267, 2009.

[125] L. S. Symington and J. Gautier, "Double-strand break end resection and repair pathway choice," Annual Review of Genetics, vol. 45, pp. 247-271, 2011.

[126] R. Kanagaraj, N. Saydam, P. L. Garcia, L. Zheng, and P. Janscak, "Human RECQ5 $\beta$ helicase promotes strand exchange on synthetic DNA structures resembling a stalled replication fork," Nucleic Acids Research, vol. 34, no. 18, pp. 5217-5231, 2006.

[127] M. McVey and S. E. Lee, "MMEJ repair of double-strand breaks (director's cut): deleted sequences and alternative endings," Trends in Genetics, vol. 24, no. 11, pp. 529-538, 2008.

[128] K. Kikuchi, H. I. Abdel-Aziz, Y. Taniguchi, M. Yamazoe, S. Takeda, and K. Hirota, "Bloom DNA helicase facilitates homologous recombination between diverged homologous sequences," Journal of Biological Chemistry, vol. 284, no. 39, pp. 26360-26367, 2009.

[129] A. Mannuss, S. Dukowic-Schulze, S. Suer, F. Hartung, M. Pacher, and H. Puchta, "RAD5A, RECQ4A, AND MUS81 have specific functions in homologous recombination and define different pathways of dna repair in arabidopsis thaliana," Plant Cell, vol. 22, no. 10, pp. 3318-3330, 2010.

[130] E. Speina, L. Dawut, M. Hedayati et al., "Human RECQL5 $\beta$ stimulates flap endonuclease 1," Nucleic Acids Research, vol. 38, no. 9, pp. 2904-2916, 2010.

[131] W. Wang and R. A. Bambara, "Human bloom protein stimulates flap endonuclease 1 activity by resolving DNA secondary structure," Journal of Biological Chemistry, vol. 280, no. 7, pp. 5391-5399, 2005.

[132] R. M. Brosh Jr., C. Von Kobbe, J. A. Sommers et al., "Werner syndrome protein interacts with human flap endonuclease 1 
and stimulates its cleavage activity," EMBO Journal, vol. 20, no. 20, pp. 5791-5801, 2001.

[133] T. Sinkunas, G. Gasiunas, C. Fremaux, R. Barrangou, P. Horvath, and V. Siksnys, "Cas3 is a single-stranded DNA nuclease and ATP-dependent helicase in the CRISPR/Cas immune system," EMBO Journal, vol. 30, no. 7, pp. 13351342, 2011.

[134] M. Fousteri, W. Vermeulen, A. A. van Zeeland, and L. H. F. Mullenders, "Cockayne syndrome A and B proteins differentially regulate recruitment of chromatin remodeling and repair factors to stalled RNA polymerase II in vivo," Molecular Cell, vol. 23, no. 4, pp. 471-482, 2006.

[135] M. Li, X. Xu, and Y. Liu, "The SET2-RPB1 interaction domain of human RECQ5 is important for transcriptionassociated genome stability," Molecular and Cellular Biology, vol. 31, no. 10, pp. 2090-2099, 2011.

[136] R. Kanagaraj, D. Huehn, A. MacKellar et al., "RECQ5 helicase associates with the C-terminal repeat domain of RNA polymerase II during productive elongation phase of transcription," Nucleic Acids Research, vol. 38, no. 22, pp. 8131-8140, 2010.

[137] O. Aygün, X. Xu, Y. Liu et al., "Direct inhibition of RNA polymerase II transcription by RECQL5,” Journal of Biological Chemistry, vol. 284, no. 35, pp. 23197-23203, 2009.

[138] O. Aygün, J. Svejstrup, and Y. Liu, "A RECQ5-RNA polymerase II association identified by targeted proteomic analysis of human chromatin," Proceedings of the National Academy of Sciences of the United States of America, vol. 105, no. 25, pp. 8580-8584, 2008.

[139] P. L. Opresko, M. Otterlei, J. Graakjær et al., "The Werner syndrome helicase and exonuclease cooperate to resolve telomeric D loops in a manner regulated by TRF1 and TRF2," Molecular Cell, vol. 14, no. 6, pp. 763-774, 2004.

[140] K. Lillard-Wetherell, A. Machwe, G. T. Langland et al., "Association and regulation of the BLM helicase by the telomere proteins TRF1 and TRF2," Human Molecular Genetics, vol. 13, no. 17, pp. 1919-1932, 2004.

[141] A. K. Ghosh, M. L. Rossi, D. K. Singh et al., "RECQL4, the protein mutated in Rothmund-Thomson syndrome, functions in telomere maintenance," Journal of Biological Chemistry, vol. 287, pp. 196-209, 2011.

[142] K. Paeschke, K. R. McDonald, and V. A. Zakian, “Telomeres: structures in need of unwinding," FEBS Letters, vol. 584, no. 17, pp. 3760-3772, 2010.

[143] D. H. Zhang, B. Zhou, Y. Huang, L. X. Xu, and J. Q. Zhou, "The human Pif1 helicase, a potential Escherichia coli RecD homologue, inhibits telomerase activity," Nucleic Acids Research, vol. 34, no. 5, pp. 1393-1404, 2006.

[144] T. Formosa and T. Nittis, "Dna2 mutants reveal interactions with Dna polymerase $\alpha$ and Ctf4, a Pol $\alpha$ accessory factor, and show that full Dna2 helicase activity is not essential for growth," Genetics, vol. 151, no. 4, pp. 1459-1470, 1999.

[145] J. Parenteau and R. J. Wellinger, "Accumulation of singlestranded DNA and destabilization of telomeric repeats in yeast mutant strains carrying a deletion of RAD27," Molecular and Cellular Biology, vol. 19, no. 6, pp. 4143-4152, 1999.

[146] G. Hauk and G. D. Bowman, "Structural insights into regulation and action of SWI2/SNF2 ATPases," Current Opinion in Structural Biology, vol. 21, pp. 719-727, 2011.

[147] P. McGlynn and R. G. Lloyd, "Action of RuvAB at replication fork structures," Journal of Biological Chemistry, vol. 276, no. 45, pp. 41938-41944, 2001.
[148] C. J. Rudolph, A. L. Upton, G. S. Briggs, and R. G. Lloyd, "Is RecG a general guardian of the bacterial genome?" DNA Repair, vol. 9, no. 3, pp. 210-223, 2010.

[149] D. V. Bugreev, O. M. Mazina, and A. V. Mazin, "Rad54 protein promotes branch migration of Holliday junctions," Nature, vol. 442, no. 7102, pp. 590-593, 2006.

[150] E. C. Minca and D. Kowalski, "Multiple Rad5 activities mediate sister chromatid recombination to Bypass DNA damage at stalled replication forks," Molecular Cell, vol. 38, no. 5, pp. 649-661, 2010.

[151] A. Blastyák, L. Pintér, I. Unk, L. Prakash, S. Prakash, and L. Haracska, "Yeast Rad5 protein required for postreplication repair has a DNA helicase activity specific for replication fork regression,” Molecular Cell, vol. 28, no. 1, pp. 167-175, 2007.

[152] Y. J. Achar, D. Balogh, and L. Haracska, "Coordinated protein and DNA remodeling by human HLTF on stalled replication fork," Proceedings of the National Academy of Sciences of the United States of America, vol. 108, pp. 14073-14078, 2011.

[153] N. Janssen, J. E. Bergman, M. A. Swertz et al., "Mutation update on the CHD7 gene involved in CHARGE syndrome," Human Mutation, vol. 33, no. 8, pp. 1149-1160, 2012.

[154] K. Gari, C. Décaillet, A. Z. Stasiak, A. Stasiak, and A. Constantinou, "The fanconi anemia protein FANCM can promote branch migration of holliday junctions and replication forks," Molecular Cell, vol. 29, no. 1, pp. 141-148, 2008.

[155] K. Gari, C. Décaillet, M. Delannoy, L. Wu, and A. Constantinou, "Remodeling of DNA replication structures by the branch point translocase FANCM," Proceedings of the National Academy of Sciences of the United States of America, vol. 105, no. 42, pp. 16107-16112, 2008.

[156] J. K. van Houdt, B. A. Nowakowska, S. B. Sousa et al., "Heterozygous missense mutations in SMARCA2 cause Nicolaides-Baraitser syndrome," Nature Genetics, vol. 44, supplement 1, pp. 445-449, 2012.

[157] Y. Tsurusaki, N. Okamoto, H. Ohashi et al., "Mutations affecting components of the SWI/SNF complex cause CoffinSiris syndrome," Nature Genetics, vol. 44, pp. 376-378, 2012. 

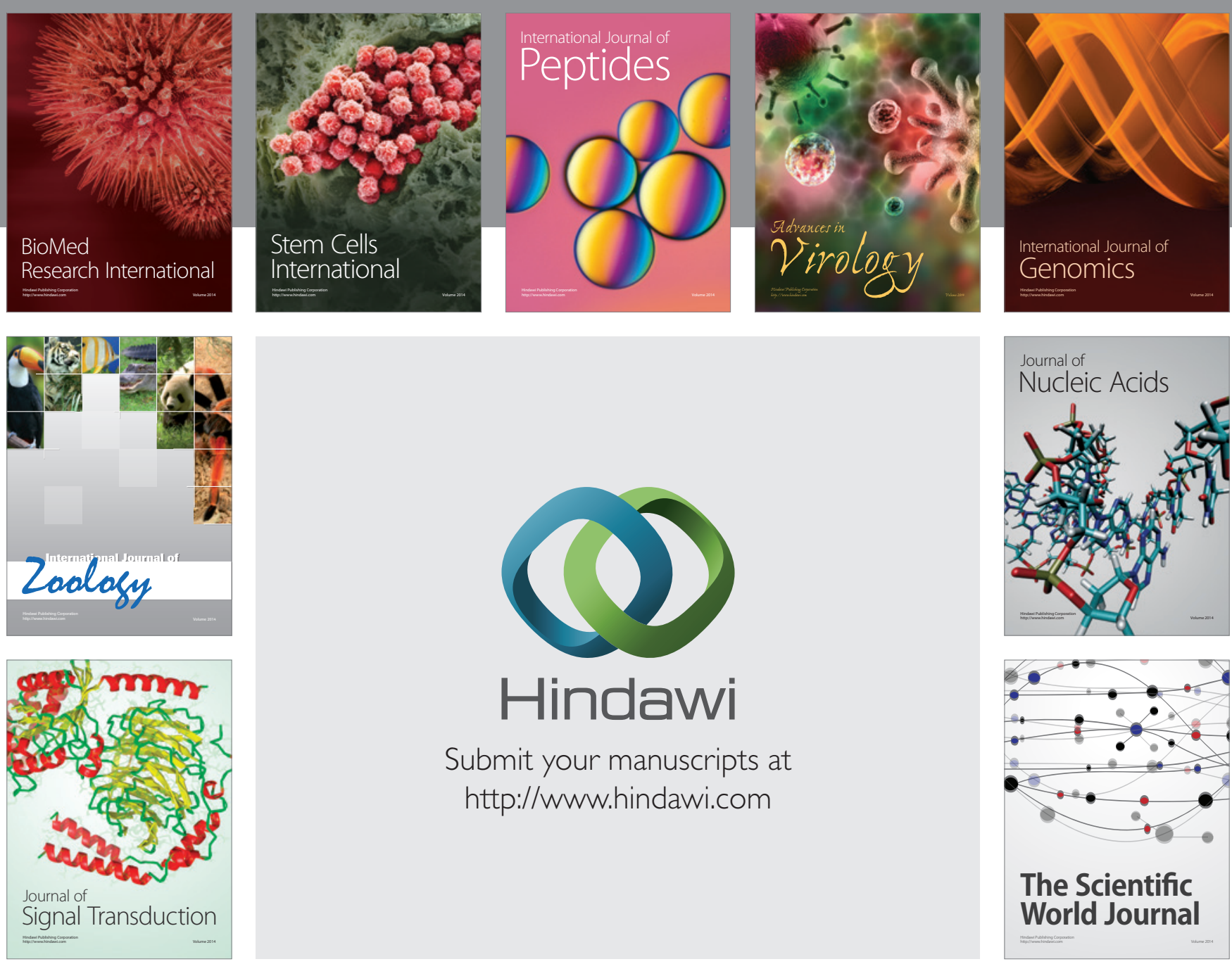

Submit your manuscripts at

http://www.hindawi.com
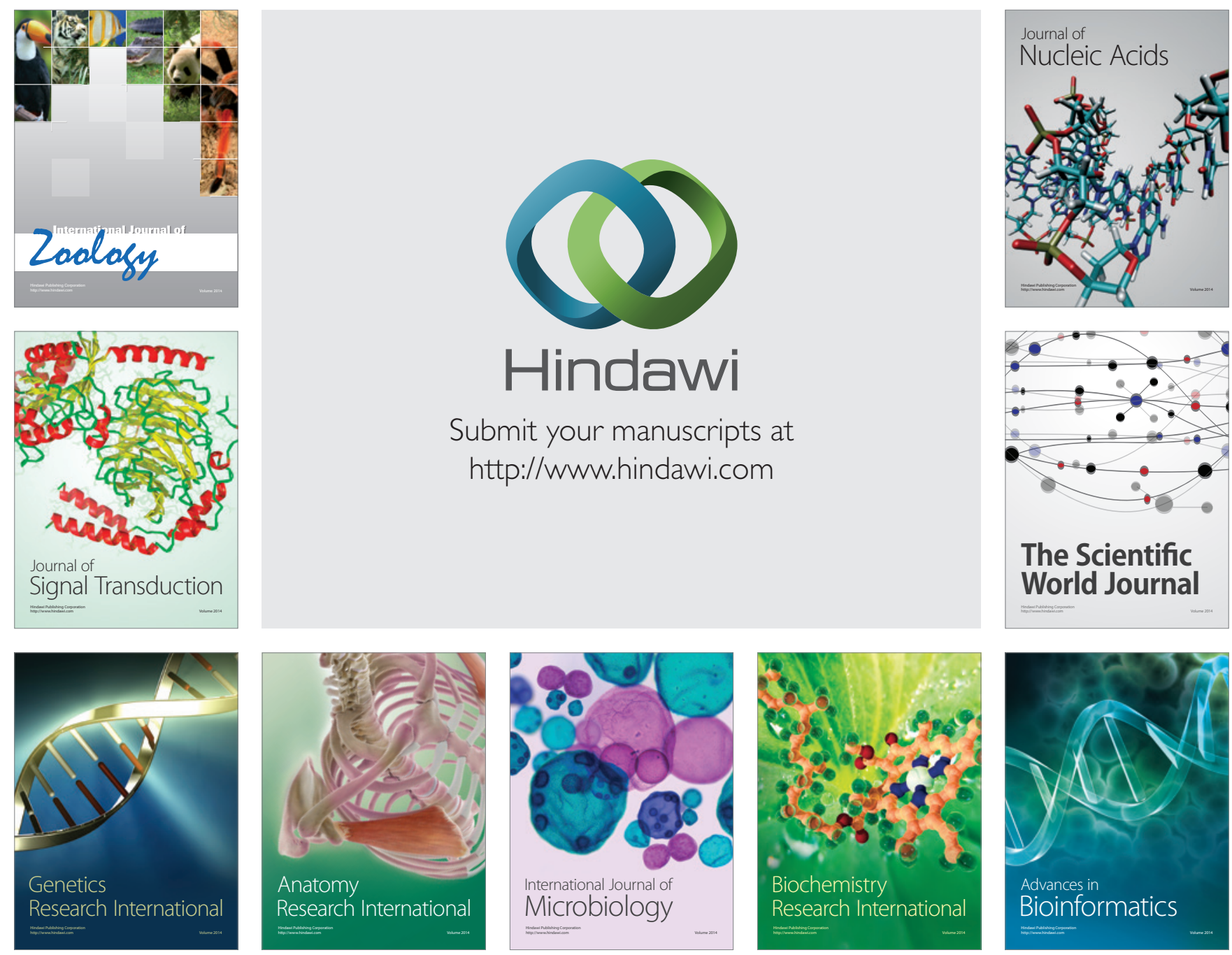

The Scientific World Journal
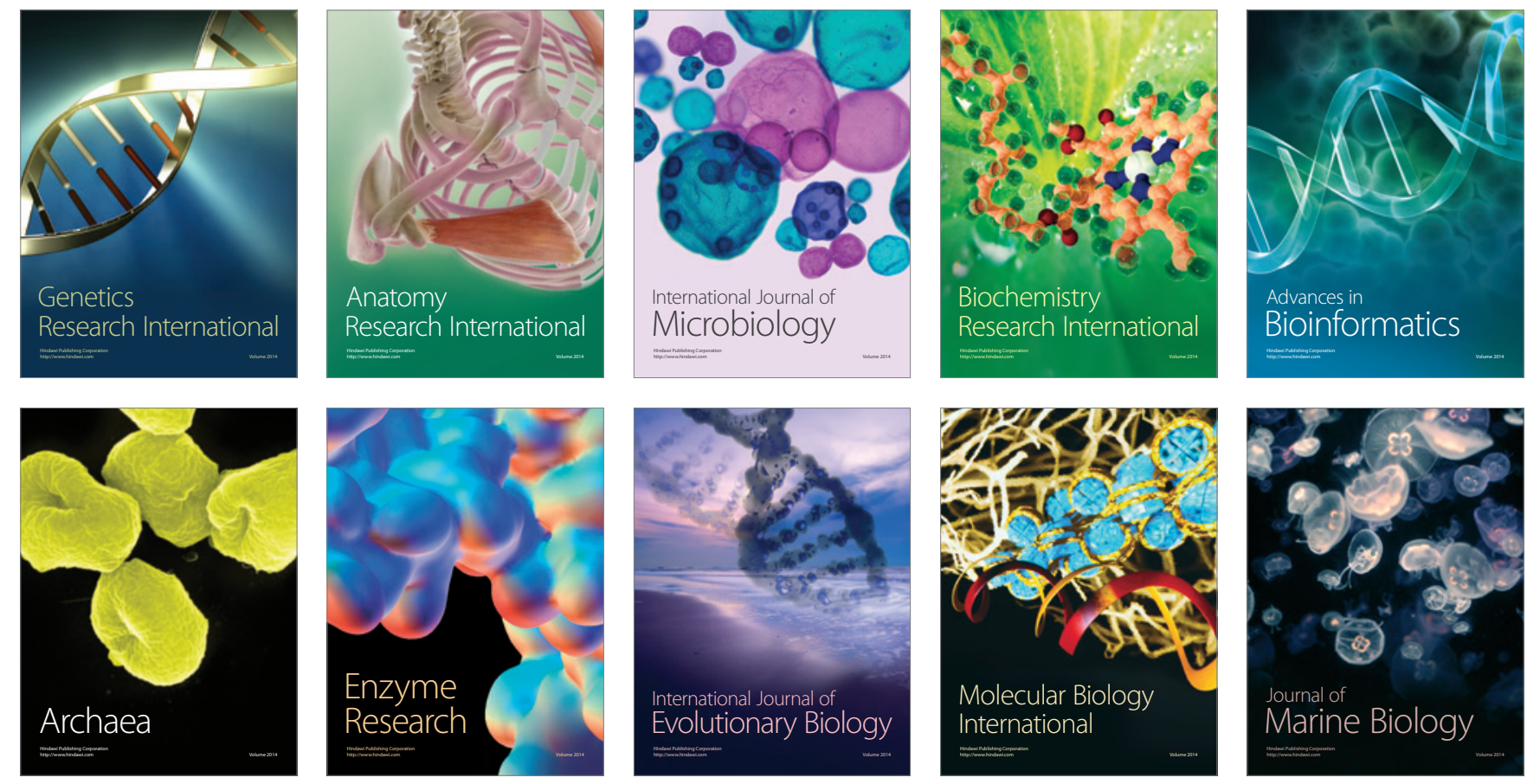